\title{
O acesso à infraestrutura e a pobreza no Brasil: uma investigação empírica
}

\author{
Access to infrastructure and poverty in Brazil: an empirical investigation
}

\author{
Victor Medeiros ${ }^{1}$ (D), Ana Maria Hermeto Camilo de Oliveira ${ }^{2}$ (D) \\ ${ }^{1}$ Programa de Pós-graduação em Economia, Centro de Desenvolvimento e Planejamento Regional (CEDEPLAR), Universidade \\ Federal de Minas Gerais (UFMG), Belo Horizonte (MG), Brasil. E-mail: victor-medeiros@cedeplar.ufmg.br \\ ${ }^{2}$ Centro de Desenvolvimento e Planejamento Regional (CEDEPLAR), Universidade Federal de Minas Gerais (UFMG), Belo \\ Horizonte (MG), Brasil. E-mail: ahermeto@cedeplar.ufmg.br
}

Como citar: Medeiros, V., \& Oliveira, A. M. H. C. (2020). O acesso à infraestrutura e a pobreza no Brasil: uma investigação empírica. Revista de Economia e Sociologia Rural, 58(2), e200520. https://doi.org/10.1590/18069479.2020 .200520

Resumo: A presente pesquisa busca estudar as relações entre o acesso à infraestrutura e a pobreza no Brasil. Objetiva-se incluir, além de características microeconômicas domiciliares, características socioeconômicas contextuais que podem ser importantes para explicar as relações entre o acesso à infraestrutura e a pobreza. Para se alcançar os objetivos propostos, estimam-se modelos logísticos hierárquicos em dois níveis: domiciliar e municipal. Os principais resultados do trabalho indicam que o acesso à infraestrutura diminui o nível de pobreza domiciliar. Os efeitos do acesso à infraestrutura sobre a pobreza, por sua vez, mostram-se heterogêneos, sendo reforçados em contextos municipais com: maior proporção de residentes em zona rural e trabalhando no setor agrícola; alta desigualdade de renda; população mais elevada; e menor taxa de fecundidade.

Palavras-chave: acesso à infraestrutura, pobreza, abordagem multinível.

\begin{abstract}
The present study seeks to study the relationship between access to infrastructure and poverty in Brazil. The objective is to include contextual features that may be important to explain the relationship between access to infrastructure and poverty, in addition to the microeconomic household characteristics. We estimated multilevel logistic models at household and municipal levels to reach the proposed objectives. The main results of the study indicated that access to infrastructure reduces the level of household poverty. In turn, the effects of the access to infrastructure on poverty are heterogeneous, while they are reinforced in municipal contexts with a greater proportion of residents in rural areas as well as working in the agricultural sector; high-income inequality; high population, and; lower fertility rate.
\end{abstract}

Keywords: access to infrastructure, poverty, multilevel approach.

\section{Introdução}

A importância atribuída ao desenvolvimento da infraestrutura econômica - definida como rodovias, ferrovias, portos e aeroportos, energia elétrica, petróleo e gás natural, biocombustíveis, tecnologias de informação e comunicação e serviços de saneamento básico - tem sido amplamente destacada desde o estudo pioneiro feito por Aschauer (1989). Pesquisas demonstram, majoritariamente, o papel positivo da infraestrutura no crescimento do produto, via aumento da produtividade dos fatores de produção e diminuição dos custos de produção e transação.

No entanto, pouco tem sido dito sobre a relação entre acesso aos serviços de infraestrutura e redução da pobreza. Como argumenta Ravallion (2004), não necessariamente maior crescimento é acompanhado por diminuição da pobreza, especificidade que ocorre quando o crescimento é seguido por elevação na desigualdade de renda. 
De acordo com Ali \& Pernia (2003), a expansão do acesso aos serviços básicos de infraestrutura traria melhores perspectivas de emprego e salário para os pobres (canal direto), via seu efeito positivo sobre a produtividade agrícola e não agrícola. O canal indireto, por sua vez, diz respeito ao fato de que, ao impulsionar a atividade econômica, os ganhos de produtividade e emprego impulsionam o próprio processo de crescimento econômico, gerando um ciclo virtuoso de expansão da renda e redução da pobreza.

Willoughby (2004) e, posteriormente, Jerome (2011) propõem outros canais pelos quais os efeitos da infraestrutura sobre a pobreza podem ser transmitidos. Com base nos "Objetivos de Desenvolvimento do Milênio", propostos pela Cúpula do Milênio das Nações Unidas (ONU) de setembro de 2000 (United Nations, 2000), os autores ressaltam a essencialidade dos bens de infraestrutura para o desenvolvimento humano. A importância dos descritos serviços não estaria ligada apenas ao seu efeito positivo sobre a renda dos indivíduos mais pobres, mas também a aspectos não monetários da pobreza, tais como melhorias na saúde, nutrição, educação e coesão social.

Nessa perspectiva, diversos estudos empíricos emergiram com a intenção de melhor definir a relação entre o acesso à infraestrutura e a pobreza. Mesmo que a base de dados e a metodologia utilizadas variem, bem como as variáveis de infraestrutura utilizadas, os resultados mais comuns confirmam que há efeitos positivos da infraestrutura sobre a redução da pobreza (Jacoby \& Minten, 2008; Dinkelman, 2011; Gonzalez-Navarro \& QuintanaDomeque, 2015; Broegaard et al., 2011; Rauniyar et al., 2011).

No caso brasileiro, no entanto, a literatura é extremamente escassa. Apenas dois estudos - Cruz et al. (2017) e Marinho et al. (2017) - analisam as relações consideradas neste estudo diretamente. Os resultados gerais demonstram relação inversa entre infraestrutura e pobreza, ou seja, melhorias infraestruturais acarretariam redução da pobreza.

Ainda que a literatura sobre infraestrutura e pobreza tenha avançado, algumas limitações ainda são visíveis, principalmente no âmbito nacional. De acordo com Calderón \& Servén (2014), o primeiro problema advém da própria variável proxy utilizada para tratar infraestrutura. Em estudos sobre infraestrutura e pobreza, variáveis de acesso dos domicílios aos serviços básicos seriam extremamente adequadas, pois captam, de fato, a distribuição desses serviços para diferentes percentis da distribuição de renda. Muitos trabalhos, no entanto, utilizam fluxos de investimentos, de caráter agregado, como variáveis proxies de infraestrutura, o que limita o entendimento sobre o estoque físico disponível para utilização, bem como não captam quem, de fato, tem acesso aos serviços (Seneviratne \& Sun, 2013; Cruz et al., 2017; Marinho et al., 2017).

Outros objetivos que pesquisas recentes (Sawada, 2015; Estache, 2010; Hansen et al., 2011) na literatura considerada neste trabalho têm buscado alcançar se referem a: melhor definir a própria relação de causalidade entre infraestrutura e pobreza; e entender o contexto no qual os indivíduos estão inseridos e, consequentemente, os possíveis efeitos heterogêneos dos serviços de infraestrutura sobre a pobreza.

A motivação em se verificar tais hipóteses decorre da discrepância do acesso à infraestrutura no Brasil, tanto em circunstâncias de desigualdade de renda quanto em relação aos contrastes locacionais. O relatório intitulado "Back to Planning: How to Close Brazil's Infrastructure Gap in Times of Austerity", elaborado pelo Banco Mundial (Raiser et al., 2017), é fonte recente que alerta sobre tais discrepâncias. De acordo com dados da Pesquisa Nacional por Amostra de Domicílios (PNAD) de 2015, entre os $40 \%$ mais pobres, apenas $21 \%$ tinham acesso à internet, por exemplo, enquanto, entre os $10 \%$ mais ricos, cerca de $85 \%$ acessavam o serviço. Além da renda, desigualdades substanciais de acesso, principalmente, a esgoto, água e internet podem ser notadas no contexto rural-urbano, bem como entre as grandes regiões.

Desta forma, o presente estudo pretende contribuir para a literatura que trata do tema infraestrutura e pobreza. O objetivo principal deste trabalho é verificar como se dá a relação entre infraestrutura e pobreza e se essa relação varia de acordo com as características contextuais (em específico, municipais) referentes às condições de vida da população e à estrutura produtiva e do mercado de trabalho, por exemplo. Em outros termos, busca-se responder às seguintes perguntas de pesquisa: existe relação entre o acesso à infraestrutura 
e a pobreza domiciliar no Brasil? Caso exista, tais relações são modificadas de acordo com o contexto municipal dos domicílios?

Para tanto, utiliza-se de modelos logísticos hierárquicos que tratam domicílios dentro de municípios, buscando captar os efeitos heterogêneos do acesso à infraestrutura sobre a pobreza, de acordo com as características socioeconômicas municipais. Portanto, propõem-se perspectivas de políticas públicas relacionadas aos setores de infraestrutura, avaliando os diferentes impactos dela sob contextos municipais distintos.

O artigo está organizado em cinco seções, além desta introdução, que buscam: descrever brevemente os determinantes contextuais da pobreza; expor a literatura especializada no tema infraestrutura e pobreza; explicitar a metodologia utilizada; demonstrar os resultados da pesquisa e discutir acerca deles; e ressaltar as principais conclusões.

\section{Determinantes da pobreza: características domiciliares e contextuais}

A presente seção pretende abordar brevemente alguns dos principais fatores que influenciam a pobreza domiciliar. Não se propõe discutir a fundo sobre essa questão, visto que essa discussão estaria aquém do escopo do trabalho, mas busca-se inserir, com base em estudos nacionais e internacionais, a importância de se levar em consideração questões domiciliares, regionais e macroeconômicas no estudo sobre a pobreza.

Como argumenta Rocha (2006), a pobreza pode assumir três perfis: o primeiro é relacionado à baixa renda per capita local; o segundo é decorrente da alta desigualdade, mesmo com a existência de alto nível de renda; o terceiro advém de alta desigualdade de renda, apesar do estabelecimento de um nível de renda per capita suficiente para atender às necessidades da população.

Além da renda e desigualdade, no entanto, uma diversidade de fatores domiciliares e contextuais, ou locacionais ${ }^{1}$, relacionam-se à pobreza. Os fatores domiciliares abrangem aspectos como condições de saúde dos moradores, nível educacional, indicadores de segurança e moradia, tamanho do domicílio, razão de dependência, estrutura etária, idade, sexo e etnia do chefe do domicílio, número de crianças, propriedades per capita, acesso a bens duráveis, acesso a serviços públicos, origem dos rendimentos domiciliares e cultura da pobreza, entre outros.

Os fatores locacionais, por sua vez, abrangem aspectos de caráter agregado, os quais buscam descrever características de municípios, grandes regiões e Estados, onde os domicílios estão inseridos, por exemplo. Entre tais variáveis pode-se citar: taxa de desemprego, baixa produtividade, indisponibilidade de serviços de saúde e educação, altas taxas de mortalidade e fecundidade e elevadas taxas de alfabetização.

Ademais, diversos estudos utilizam variáveis de economia regional, as quais buscam captar as características da localidade em que a família está inserida, tais como: população total, dummies municipais e locacionais, variáveis relativas à estrutura produtiva urbana e relacionadas à oferta de mão de obra qualificada (Myrdal, 1957; North, 1977; Lima \& Simões, 2010) $)^{2}$.

Uma vez descritas as principais variáveis de cunho domiciliar, locacional e regional determinantes da pobreza, pode-se levar em consideração a inserção das variáveis de infraestrutura, tema central deste trabalho, no contexto da diminuição da pobreza. A próxima seção busca explorar com maiores detalhes a relação entre o acesso à infraestrutura e a

\footnotetext{
${ }^{1}$ Como argumentam Jalan \& Ravallion (2002), mesmo controlando a pobreza por fatores domiciliares/familiares, uma parcela considerável da pobreza seria determinada pela denominada "geographical capital", ou seja, por uma diversidade de fatores vinculados ao local em que uma família se estabelece. Outros estudos que argumentam no mesmo sentido são, por exemplo, os de Hulme et al. (2001), Rocha (2006) e Haughton \& Khandker (2009). Revisão de literatura mais detalhada pode ser obtida em Schiavon (2014).

${ }^{2}$ Além das teorias de Myrdal e North, diversas outras buscam explicar a dinâmica regional, isto é, o processo de determinação da renda urbana, que é a expressão e a causa do movimento do capital no espaço, tais como aquelas de Albert Hirschman, François Perroux e Jacques Boudeville. Dadas as existentes vantagens ou desvantagens comparativas dos espaços econômicos, propagam-se movimentos de migração do capital, os quais resultam em determinada dinâmica regional, ou seja, em relativa expansão ou estagnação do processo de acumulação em uma região. Revisão de literatura, neste sentido, pode ser encontrada, por exemplo, em Lima \& Simões (2010).
} 
pobreza por meio da descrição de alguns dos principais estudos internacionais e nacionais e, a partir destes, estabelecer os principais pontos ainda pouco discutidos nessa literatura.

\section{O acesso à infraestrutura e a pobreza: relações, literatura e pontos em aberto}

Como argumentam López (2004) e Ravallion (2004), não necessariamente maior crescimento gera redução da pobreza. Tal ocasião ocorreria, pois, ainda que o efeito do crescimento fosse positivo, poderia acontecer efeito negativo na distribuição de renda, gerando aumento da pobreza. Resultados nesse sentido podem ser encontrados em Banerjee (2004) e Khandker \& Koolwal (2007). No que tange ao estudo sobre os impactos diretos do acesso à infraestrutura sobre a pobreza, a literatura, tanto em aspectos teóricos quanto empíricos, é demasiadamente escassa, principalmente no âmbito nacional.

Algumas pesquisas emergiram com o intuito de melhor explicar os canais pelos quais a infraestrutura seria capaz de reduzir a pobreza. Ali \& Pernia (2003) propõem um esquema em que a infraestrutura afeta a pobreza por meio de dois mecanismos, com ênfase nos países em desenvolvimento. O primeiro, nomeado como canal direto, diz respeito ao efeito sobre a distribuição de renda: melhorias nos setores de transportes, telecomunicações e energia, por exemplo, trariam mais perspectivas de emprego e ganhos salariais para os pobres, visto que tais setores proporcionam aumento da produtividade agrícola e não agrícola.

O segundo, canal indireto, diz respeito aos efeitos da ampliação da infraestrutura sobre o crescimento do produto: investimentos em infraestrutura levam ao aumento no nível de atividade econômica, impulsionando, assim, a geração de empregos e renda do trabalho. As relações entre infraestrutura e ambos os mecanismos mencionados acarretam, em via última, redução da pobreza, mediante aumento de renda e consumo real dos indivíduos considerados pobres.

Um aspecto fundamental do esquema de Ali \& Pernia (2003) é a relação indireta entre infraestrutura e pobreza por meio de crescimento econômico rural. Em síntese, o que os autores argumentam é que a maior parte da população, composta de trabalhadores não detentores de terra, depende de ganhos salariais para sua sobrevivência. Tais ganhos, por sua vez, necessitam da produtividade agrícola e dos empregos agrícola e não agrícola. Como os trabalhadores mais pobres não possuem a propriedade dos meios de produção, o aumento da produtividade agrícola, em decorrência da expansão na infraestrutura, pode gerar maior bem-estar para os segmentos populacionais de menor renda.

Complementarmente, Jones (2011) elabora um esquema com outros quatro mecanismos essenciais pelos quais a provisão de infraestrutura pode causar diminuição da pobreza. O primeiro se refere à redução dos custos de produção, derivados de menor custo de energia, transportes e serviços de conexão, por exemplo, internet e telefone. O segundo mecanismo, ao tratar da infraestrutura como insumo de produção, relaciona-se ao efeito daquela sobre a expansão da capacidade produtiva total da economia. Por sua vez, o terceiro mecanismo estaria ligado ao fato de que melhorias nos transportes e na comunicação, por exemplo, aumentam a eficiência do mercado por meio de maior conexão e melhores instalações econômicas. A infraestrutura de telecomunicações também fornece ferramentas e informações necessárias para que os mercados funcionem de forma mais integrada e eficiente. Por fim, o quarto mecanismo diz respeito ao aumento do acesso a necessidades básicas por parte dos indivíduos, por exemplo, água e esgoto tratados, energia elétrica, meios de comunicação etc., ou seja, a redução da pobreza em seu aspecto multidimensional ${ }^{3}$.

Nessa perspectiva, o desenvolvimento da infraestrutura promoveria, entre outros aspectos, melhor acesso a estradas, escolas, saúde e outros bens e serviços essenciais. A importância do setor público consistiria em garantir condições adequadas - advindas de regras claras, bem como pelo estabelecimento de um sistema regulatório eficiente - para a

\footnotetext{
${ }^{3} \mathrm{~A}$ análise de Sen (2000), respaldada no conceito de pobreza multidimensional, introduz parâmetros fundados nos princípios da justiça social, com a criação de um novo conceito de bem-estar, considerando a pobreza um fenômeno não mais restrito a meios e recursos que os indivíduos possuem, mas que abrange sua liberdade de escolha em relação à sua proposição de vida.
} 
alavancagem de recursos nos setores envolvidos, seja pelo próprio investimento estatal, seja por meio de parcerias público-privadas (PPP) (Jones, 2011).

No descrito contexto, alguns estudos empíricos foram propostos com o intuito de melhor estabelecer a relação entre o acesso à infraestrutura e a redução da pobreza, mais do que o impacto de tais setores sobre o crescimento da renda. Ainda que a base de dados e a metodologia utilizadas variem, assim como as variáveis de infraestrutura adotadas, os resultados majoritários contribuem para confirmar a hipótese de que há efeitos positivos da infraestrutura sobre a redução da pobreza (Gibson \& Rozelle, 2003; Jacoby, 2000; Jacoby \& Minten, 2008; Jalan \& Ravallion, 2003; Lokshin \& Yemtsov, 2004, 2005).

No caso brasileiro, há apenas dois artigos que tratam do tema em análise diretamente: Cruz et al. (2017) e Marinho et al. (2017), ambos de âmbito macroeconômico. Tais estudos utilizaram como variáveis proxies de infraestrutura investimentos estaduais em setores estratégicos como transportes, energia, entre outros. Os resultados gerais demonstram relação inversa entre infraestrutura e pobreza, ou seja, melhorias infraestruturais acarretariam redução da pobreza.

No entanto, além da escassez de investigações na literatura nacional, algumas limitações surgem na própria definição das variáveis de infraestrutura. Medidas de infraestrutura baseadas em fluxos de gastos (investimentos públicos, por exemplo) possivelmente serão proxies fracas ${ }^{4}$ para a acumulação de infraestrutura, ou seja, não se tratando apenas de investimentos nos setores relacionados, mas sim do estoque físico e efetivo de infraestrutura. Ademais, muitos estudos não levaram em consideração o acesso dos indivíduos aos serviços de infraestrutura analisados e as interações entre as variáveis de cunho domiciliar e aquelas de caráter locacional e regional.

Como argumentam Calderón \& Servén (2014), variáveis que tratam do acesso aos serviços de infraestrutura seriam extremamente adequadas para abordar temas como pobreza e desigualdade, pois conseguem captar, de fato, a distribuição desses serviços para diferentes percentis da distribuição da renda. No entanto, a escassez de dados sobre o acesso aos serviços, tanto entre países e regiões quanto ao longo do tempo, muitas vezes dificulta a análise econométrica.

Em investigações de caráter macroeconômico, a utilização de dados agregados sobre o acesso, isto é, sem uma quebra em percentis de renda, parte do pressuposto implícito de que as mudanças no acesso aos serviços afetam, principalmente, os segmentos mais pobres da população. Todavia, de acordo com Estache \& Fay (2007), nem sempre os mais pobres são os mais beneficiados, o que tornaria a análise de cunho agregado limitada ${ }^{5}$ em termos da interpretação da variável de infraestrutura como acessibilidade.

Desta forma, a abordagem microeconômica, que é utilizada neste estudo, tem sido amplamente adotada para tratar do tema infraestrutura e pobreza. Como propõem Sawada (2015), Estache (2010) e Hansen et al. (2011), estudos recentes nesse âmbito têm buscado alcançar alguns objetivos fundamentais para o avanço da literatura analisada nesta seção, a saber: melhor definir a própria relação de causalidade entre infraestrutura e pobreza; entender o contexto em que os indivíduos estão inseridos e, consequentemente, os possíveis efeitos heterogêneos dos serviços de infraestrutura sobre a pobreza; e levar em consideração a hipótese de um viés de seleção nessa estimativa. Tal hipótese decorre do fato de que a infraestrutura pode ser alocada de maneira desigual entre as famílias, tendendo a ficar concentrada em regiões mais ricas e urbanizadas, por exemplo.

\footnotetext{
4De acordo com Calderón \& Servén (2014) e Seneviratne \& Sun (2013), variáveis do tipo investimento público poderiam não representar adequadamente o nível de infraestrutura de determinado país ou região, visto que a provisão desses serviços poderia ter grande participação privada. De outro modo, não necessariamente os investimentos seriam transformados em infraestrutura física por causa de possíveis ineficiências na seleção e implementação de projetos, bem como ineficiências baseadas na definição e resolução de contratos públicos, além de corrupção. Ademais, no caso brasileiro, a maioria dos investimentos públicos em infraestrutura é de cunho federal, o que tornaria limitada a variável investimento estadual nos setores relacionados.

${ }^{5}$ Para o caso do setor de saneamento, por exemplo, segundo Saiani et al. (2013), existe desigualdade de acesso aos serviços de água e esgoto nos municípios brasileiros por causa de fatores como educação, densidade demográfica, renda municipal per capita e aspectos políticos.
} 
Ainda que os descritos trabalhos tenham avançado em definir as relações entre infraestrutura e redução da pobreza, eles não estudaram os determinantes da pobreza em diferentes dimensões, ou seja, não levaram em conta as possíveis interações entre determinantes domiciliares e aqueles de caráter locacional, por exemplo. Broegaard et al. (2011) e Rauniyar et al. (2011) enfocam os efeitos econômicos e produtivos heterogêneos dos serviços de infraestrutura em diferentes contextos. Os resultados indicam que esses efeitos, de fato, variam entre regiões e entre zonas situadas dentro dessas regiões e grupos socioeconômicos distintos.

Neste sentido, outra forma adequada ao estudo da pobreza, mas ainda pouco comum no entendimento específico da relação pobreza e infraestrutura, é a utilização de modelos hierárquicos. A grande vantagem de modelos multiníveis seria possibilitar a análise das variâncias dentro e entre grupos distintos e determinar como as relações de certas variáveis domiciliares com a pobreza se dão de maneira heterogênea, em circunstâncias municipais diferentes. Embora o foco não estivesse voltado ao estudo do impacto do acesso à infraestrutura sobre a pobreza, Schiavon (2014) encontrou que é importante o contexto regional em que o domicílio está inserido para determinar os padrões de pobreza no Brasil. No presente estudo, o interesse maior é verificar como a relação entre infraestrutura e pobreza varia de acordo com as características municipais referentes às condições de vida da população e à estrutura produtiva e do mercado de trabalho, por exemplo.

Em síntese, uma diversidade de estudos recentes tem buscado melhor definir as relações existentes entre infraestrutura e pobreza. No entanto, a descrita literatura é escassa para o caso brasileiro, principalmente no entendimento do acesso à infraestrutura como um microdeterminante da pobreza. Ademais, metodologias que avaliem variáveis explicativas da pobreza em diferentes níveis ainda são pouco utilizadas para o estudo da associação entre infraestrutura e pobreza, o que indica possibilidade para avanço na literatura tratada nesta seção.

\section{Materiais e métodos}

A metodologia adotada, seguindo os objetivos propostos neste artigo, foi o modelo econométrico de escolha binária aplicado à estrutura organizacional hierárquica da base de dados, em que as observações de análise são agrupadas em diferentes grupos (domicílios dentro de municípios). Essa metodologia permite solucionar problemas referentes ao tratamento de variáveis dependentes discretas, bem como contornar possíveis limitações advindas da estrutura hierarquizada dos dados.

\subsection{Descrição das variáveis}

Para se inferir se a pobreza foi influenciada pelo acesso à infraestrutura no ano de 2010, utilizaram-se três conjuntos de variáveis: a de interesse, ou seja, se a família era considerada pobre ou não; as proxies, para o acesso das famílias aos serviços de infraestrutura; e as de controle, divididas em características domiciliares/familiares e características municipais.

Os atributos do domicílio ou da família foram captados por algumas características do chefe do domicílio, tais como sexo, faixa etária, cor, escolaridade, se vivia ou não com um(a) companheiro(a), se estava empregado ou não e também pelo número de moradores do domicílio. As características do município, por sua vez, foram descritas pelo percentual de indivíduos residentes na zona rural, percentual de indivíduos trabalhando no setor agrícola, logaritmo natural da população, percentual da população com ensino superior completo, percentual de ocupados trabalhando no setor informal, taxa de fecundidade total e Índice de Gini do rendimento domiciliar per capita. O Quadro 1A no Apêndice exibe maiores detalhes das variáveis utilizadas no trabalho. Todas as variáveis têm como fonte o Censo Demográfico de 2010, visto que essa base permite a hierarquização dos dados em domicílios e municípios proposta no trabalho.

As variáveis de infraestrutura foram criadas de acordo com os padrões da literatura nacional e internacional, considerando os diversos setores que compõem o conceito de infraestrutura econômica. Uma limitação deste estudo como consequência da restrição da 
base de dados se refere à não inclusão de uma variável proxy de acesso aos serviços do setor de transportes, visto a inexistência desta em âmbito domiciliar ou municipal. Desta forma, criaram-se variáveis para representar os setores de energia, telecomunicações e saneamento básico. Para o setor energético, a variável energia assumiu o valor 1 , se o domicílio fosse servido com energia elétrica de companhia distribuidora, ou 0 , se fosse o contrário. No setor de telecomunicações, três variáveis foram utilizadas: celular, que assumiu o valor 1 , se o domicílio possuísse telefone celular disponível, ou 0 , se fosse o contrário; fixo, que assumiu o valor 1 , se o domicílio possuísse linha telefônica convencional instalada, ou 0 , se fosse o contrário; e telecomunicações, que assumiu valor 1, se existisse no domicílio acesso a celular e/ou telefone fixo ${ }^{6}$, ou 0 , se fosse o contrário. Por fim, o setor de saneamento básico foi representado por duas variáveis, as quais podem ser descritas como: água, que assumiu valor 1, se o domicílio estivesse ligado a uma rede geral de distribuição de água, ou 0, se fosse o contrário; e esgoto, que assumiu valor 1, se o domicílio estivesse ligado ao sistema de coleta, ou 0 , se fosse o contrário.

Em seguida, as variáveis desagregadas descritas no parágrafo anterior foram utilizadas para gerar novas variáveis, com o objetivo de melhor descrever o aspecto multidimensional ${ }^{7}$ da infraestrutura, como sugerem Calderón \& Servén (2014). A primeira agregação, saneamento, assumiu valor 1 , se o domicílio possuísse acesso à água e esgoto, ou 0 , se fosse o contrário. Por fim, a variável infraestrutura, a qual é utilizada na modelagem econométrica como proxy para o acesso dos domicílios à infraestrutura, assumiu valor, 1 se o domicílio possuísse acesso aos serviços de energia, telecomunicações e saneamento, ou 0, se fosse o contrário.

Como variável resposta foi considerada uma variável binária que assumiu valor 1 , se a família fosse considerada pobre, ou 0 , se fosse o contrário. Nesse sentido, a família foi considerada pobre caso tivesse renda domiciliar per capita mensal média inferior à linha de pobreza (R\$ 140,00), sendo esta última calculada como o dobro da linha de extrema pobreza (R\$ 70,00). A linha de pobreza utilizada neste estudo foi definida pelo Ministério do Desenvolvimento Social e Combate à Fome (MDS) ${ }^{8}$ (Brasil, 2011).

\subsection{A pobreza, o acesso à infraestrutura e o contexto municipal: o modelo logístico hierárquico}

O entendimento das relações entre pobreza e acesso à infraestrutura proposto neste trabalho pode trazer dois problemas de cunho metodológico que devem ser solucionados. O primeiro é relacionado ao fato de a variável dependente ser binária, podendo ser contornado por meio da utilização de um modelo Logit, visto que estimações geradas via método de Mínimos Quadrados Ordinários (MQO) poderiam ser inadequadas ${ }^{9}$. O segundo é advindo da hierarquização dos dados em níveis distintos, podendo ser solucionado por meio da utilização de modelos multiníveis. Desta forma, o modelo econométrico utilizado é o modelo logístico hierárquico.

De acordo com Guo \& Zhao (2000), os modelos logísticos hierárquicos são convenientes para o estudo em questão, ou seja, para captar os determinantes domiciliares e locacionais

\footnotetext{
${ }^{6}$ Neste caso, preferiu-se utilizar a soma das duas variáveis em vez de escolher entre uma outra. Essa escolha se deve ao fato de que esses dois serviços podem ser substitutos, ao contrário da forte complementariedade existente no setor de saneamento básico.

${ }^{7} \mathrm{~A}$ infraestrutura compreende serviços que variam desde transportes até a provisão de água tratada. No entanto, muitos estudos levam um único indicador como proxy para infraestrutura. Ao se omitir outros indicadores de infraestrutura, que são relevantes, ocasionam-se inferências inválidas.

${ }^{8}$ Esta é uma linha absoluta que representa o custo da compra de uma cesta de itens essenciais que permitem uma pessoa alcançar o patamar absoluto mínimo de satisfação de certas necessidades básicas. Em outras palavras, considera-se em situação de pobreza aqueles domicílios que não possuem uma renda mínima que os permitam acessar os bens e serviços considerados básicos e essenciais. Portanto, a pobreza é tratada em uma via unidimensional, abordagem que é indicada quando se quer referir a países com uma grande proporção de população urbana e uma grande economia de mercado, como é o caso do Brasil (Expert Group on Poverty Statistics, 2006).

${ }^{9} \mathrm{~A}$ técnica MQO, no entanto, não garante que as probabilidades condicionais preditas se encontrem no intervalo entre 0 e 1. Ademais, é possível mostrar que as estimativas do MPL, caso a variável dependente seja dicotômica, serão viesadas e o termo de erro será heterocedástico (Aldrich \& Nelson, 1984).
} 
da pobreza, pois: levam em consideração a hierarquia dos dados, ou seja, como as covariadas dispostas em diferentes níveis da estrutura hierárquica afetam a variável resposta, bem como analisam de que forma as interações entre covariadas de diferentes níveis afetam a variável dependente; corrigem possíveis vieses nos parâmetros resultantes dos agrupamentos dos dados; proveem erros-padrão $\operatorname{corretos}^{10} \mathrm{e}$, consequentemente, corretos intervalos de confiança e testes de significância; e as estimativas da variância e covariância dos efeitos aleatórios em diferentes níveis possibilitam decompor a variância total na variável de resultado em parcelas associadas a cada nível analisado.

A utilização do modelo logístico hierárquico possibilita, então, uma pesquisa sobre as relações entre as variáveis que caracterizam os domicílios (nível 1) e aquelas que caracterizam os municípios (nível 2). Para facilitar o entendimento, o método será descrito de acordo com sua complexidade e com o que será feito na aplicação econométrica, ou seja, descreve-se inicialmente o modelo que inclui apenas variáveis explicativas de primeiro nível e suas propagações com intercepto aleatório, interceptos e inclinações aleatórios e, em seguida, incluem-se as variáveis de segundo nível e suas interações com as covariadas de primeiro nível.

O modelo mais simplificado tem $y_{i j}$ como variável dependente binária para o domicílio i no município j, $x_{i j}$ como variável explicativa no âmbito do domicílio, $\beta_{0 j}$ como vetor de interceptos aleatórios, $\beta_{i j}$ como matriz de coeficientes aleatórios para cada variável de primeiro nível de acordo com o agrupamento j, e $r_{i j}$ é o resíduo aleatório de nível 1. De acordo com Guo \& Zhao (2000), a probabilidade de a família ser pobre é dada por $p_{i j}=\operatorname{Pr}\left(y_{i j}=1\right)$, e, assumindo $p_{i j}$ modelado por uma função de ligação logística, pode-se descrever o Modelo 1 como:

$\log \left[\frac{p_{i j}}{1-p_{i j}}\right]=\beta_{0 j}+\beta_{l j} X_{i j}+r_{i j}$ (Nível 1)

$\beta_{0 j}=\gamma_{00}+u_{0 j}$ (Nível 2)

$\beta_{l j}=\gamma_{10}$ (Nível 2)

$\log \left[\frac{p_{i j}}{1-p_{i j}}\right]=\gamma_{00}+\gamma_{10} X_{i j}+u_{0 j}+r_{i j}$ (Modelo 1)

A Equação 1 especifica o modelo no primeiro nível, também conhecido como modelo de coeficientes aleatórios. Tal nomeação deriva do fato de que o índice j dos coeficientes $\beta_{0 j} \mathrm{e}$ $\beta_{l j}$ assume valores diferentes para cada grupo j. Em relação às equações de nível dois, $u_{0 j}$ é o resíduo aleatório de nível 2, $\gamma_{00}$ é o intercepto de nível 2 e $\gamma_{10}$ é o coeficiente relacionado à característica domiciliar. No Modelo 1, os efeitos aleatórios dos níveis 1 e 2 estão representados por $r_{i j}$ e $u_{0_{j}}$, respectivamente. Assume-se que ambos são independentes e seguem distribuição logística padronizada com média zero e variâncias constantes iguais a $\sigma_{e}^{2}=\frac{\pi^{2}}{3}$ (variância dentro do grupo) e $\sigma_{u 0}^{2}$ (variância entre grupos). Nesse modelo inicial, os interceptos variam de uma unidade j para outra, enquanto as inclinações são as mesmas para todas as unidades do nível 2.

\footnotetext{
${ }^{10}$ Quando os dados são agrupados, é provável que observações em um mesmo agrupamento sejam similares entre si; logo, as observações não são independentes. Neste caso, o pressuposto de independência é violado, e os modelos lineares e binários tradicionais tendem a subestimar os erros-padrão.
} 
A primeira ampliação do modelo consiste em também variar as inclinações de uma unidade de nível 2 para outra também de nível 2. A equação de nível 1 é novamente identificada pela Equação 1, com a única mudança se referindo à equação $\beta_{l j}$ de nível 2 , visto que $\beta_{0 j}$ é identicamente dado por (2). O Modelo 2 pode ser descrito como:

$\log \left[\frac{p_{i j}}{1-p_{i j}}\right]=\beta_{0 j}+\beta_{1 j} X_{i j}+r_{i j}$ (Nível 1)

$\beta_{0 j}=\gamma_{00}+u_{0 j}$ (Nível 2)

$\beta_{1 j}=\gamma_{10}+u_{1 j}$ (Nível 2)

$\log \left[\frac{p_{i j}}{1-p_{i j}}\right]=\gamma_{00}+\gamma_{10} X_{i j}+u_{1 j} X_{i j}+u_{0 j}+r_{i j}$ (Modelo 2)

A diferença deste modelo para o anterior é que o efeito aleatório de nível 2 afeta tanto o intercepto $\left(u_{0 j}\right)$ quanto a inclinação $\left(u_{1 j}\right)$.

A subsequente ampliação do modelo consiste em incluir variáveis explicativas de ambos os níveis. A equação de nível 1 permanece como a Equação 1, enquanto as equações de segundo nível são modificadas. O Modelo 3 é descrito como:

$\log \left[\frac{p_{i j}}{1-p_{i j}}\right]=\beta_{0 j}+\beta_{1 j} X_{i j}+r_{i j}$ (Nível 1)

$\beta_{0 j}=\gamma_{00}+\gamma_{0 I} W_{j}+u_{0 j}$ (Nível 2)

$\beta_{1 j}=\gamma_{10}+u_{1 j}$ (Nível 2)

$\log \left[\frac{p_{i j}}{1-p_{i j}}\right]=\gamma_{00}+\gamma_{10} X_{i j}+\gamma_{0 I} W_{j}+u_{1 j} X_{i j}+u_{0 j}+r_{i j}$ (Modelo 3)

Em que: $W_{j}$ é a variável explicativa de segundo nível, $\gamma_{01}$ é o coeficiente da regressão associado aos efeitos das variáveis explicativas do nível do município na relação estrutural do nível do domicílio.

Por fim, a última extensão do modelo inclui as interações entre as variáveis de níveis distintos em que, neste estudo especificamente, serão interações entre as variáveis de nível 2 e a variável de infraestrutura. A equação de nível 1 permanece como a Equação 1, enquanto as equações de segundo nível são dadas por:

$\log \left[\frac{p_{i j}}{1-p_{i j}}\right]=\beta_{0 j}+\beta_{1 j} X_{i j}+r_{i j}$ (Nível 1)

$\beta_{0 j}=\gamma_{00}+\gamma_{01} W_{j}+u_{0 j}$ (Nível 2) (8) $\beta_{1 j}=\gamma_{10}+\gamma_{11} W_{j}+u_{1 j}$ (Nível 2) 
$\log \left[\frac{p_{i j}}{1-p_{i j}}\right]=\gamma_{00}+\gamma_{10} X_{i j}+\gamma_{0 I} W_{j}+\gamma_{11} W_{j} X_{i j}+u_{1 j} X_{i j}+u_{0 j}+r_{i j}$ (Modelo 4)

Nessa especificação, permite-se avaliar questões importantes para o estudo em questão, tais como: o quanto das variações na variável dependente referente à pobreza é explicado pelas variações de cada um dos grupos e como as características locacionais e domiciliares se relacionam para explicar a pobreza.

Nos modelos das Equações 4, 7 e 10, a função densidade de probabilidade é idêntica à observada para uma regressão logística comum, a regressão segue uma estimativa por máxima verossimilhança e a solução requer macro e microinterações numéricas. Maiores informações sobre o modelo logístico hierárquico podem ser obtidas em Hox $(1998,2017)$ e Guo \& Zhao (2000).

Por causa da não linearidade do modelo Logit, os coeficientes não podem ser interpretados como a influência quantitativa das variáveis independentes sobre a probabilidade de que a variável dependente assuma o valor 1. A análise dos resultados pode ser feita pela interpretação das odds ratio (razões de chance). Uma razão de chance igual a 1 indica que o evento sob estudo é igualmente provável de ocorrer nos dois grupos de comparação. Uma razão de chance maior do que 1 indica que o evento tem maior probabilidade de ocorrer no primeiro grupo. Finalmente, uma razão de chance menor do que 1 indica que a probabilidade é menor no primeiro grupo do que no segundo.

\section{Resultados e discussão}

\subsection{Características gerais e de acesso aos serviços de infraestrutura nos domicílios pobres brasileiros}

A presente subseção tem como objetivo analisar de forma mais detalhada as particularidades e as precariedades domiciliares brasileiras. De acordo com a Tabela 1, observa-se que: $14,4 \%$ da amostra estava na considerada situação de pobreza; $41 \%$ dos domicílios eram chefiados por mulheres; $66 \%$ dos chefes viviam com seus cônjuges; $2 \%$ dos chefes possuíam ensino superior completo; o número médio de moradores por domicilio foi 4,10; e 80\% dos chefes dos domicílios considerados pobres estavam empregados em 2010.

Tabela 1 - Estatísticas descritivas domiciliares: amostra total, pobres e não pobres, 2010.

\begin{tabular}{|c|c|c|c|c|c|c|}
\hline \multirow{2}{*}{ Variável/indicador } & \multicolumn{2}{|c|}{ Total } & \multicolumn{2}{|c|}{ Pobres } & \multicolumn{2}{|c|}{ Não pobres } \\
\hline & Média & DP & Média & DP & Média & DP \\
\hline pobre & 0,144 & 0,351 & 1,000 & 0,000 & 0,000 & 0,000 \\
\hline $\begin{array}{l}\text { sexochefam } \\
\text { idadechefea }\end{array}$ & 0,386 & 0,487 & 0,407 & 0,491 & 0,383 & 0,486 \\
\hline 1 & 0,225 & 0,417 & 0,285 & 0,452 & 0,213 & 0,410 \\
\hline 2 & 0,221 & 0,415 & 0,237 & 0,425 & 0,219 & 0,413 \\
\hline 3 & 0,177 & 0,382 & 0,156 & 0,363 & 0,181 & 0,385 \\
\hline 4 & 0,203 & 0,402 & 0,085 & 0,280 & 0,224 & 0,417 \\
\hline corchefa & 0,499 & 0,500 & 0,321 & 0,467 & 0,531 & 0,499 \\
\hline $\begin{array}{c}\text { companheiro } \\
\text { escchefea }\end{array}$ & 0,656 & 0,475 & 0,660 & 0,474 & 0,654 & 0,476 \\
\hline 1 & 0,152 & 0,359 & 0,133 & 0,339 & 0,155 & 0,362 \\
\hline 2 & 0,232 & 0,422 & 0,115 & 0,319 & 0,253 & 0,435 \\
\hline 3 & 0,105 & 0,306 & 0,020 & 0,140 & 0,120 & 0,325 \\
\hline empchefea & 0,957 & 0,202 & 0,804 & 0,397 & 0,976 & 0,152 \\
\hline moradores & 3,307 & 1,678 & 4,098 & 2,099 & 3,161 & 1,549 \\
\hline infraestrutura & 0,506 & 0,500 & 0,259 & 0,438 & 0,551 & 0,497 \\
\hline
\end{tabular}

Fonte: elaboração própria a partir de Instituto Brasileiro de Geografia e Estatística (2010). DP significa desvio-padrão; Min significa valor mínimo; Max significa valor máximo. 
Em uma breve análise comparativa com domicílios considerados não pobres ou com a amostra completa (pobres e não pobres), nota-se que, nos domicílios pobres, houve maior percentagem de chefes do domicílio do sexo feminino, concentração de chefes em faixas etárias mais baixas (mais jovens), maior percentagem de chefes negros e vivendo sem o cônjuge, bem como menor percentagem de chefes com ensino superior completo, além de maior número médio de moradores.

Em relação às variáveis municipais (Tabela 2), a amostra utilizada neste trabalho é caracterizada por: domicílios que se encontravam, na média, em municípios com 1.286.627 habitantes; $86 \%$ da população era situada na zona urbana; $10 \%$ trabalhavam no setor não agrícola; apenas $11,18 \%$ da população possuía formação em ensino superior; $45 \%$ trabalhavam no setor informal; o índice de Gini médio municipal foi igual a 0,53; e a taxa de fecundidade total teve média igual a 1,98.

Tabela 2 - Estatísticas descritivas municipais, 2010.

\begin{tabular}{ccccc} 
Variável/indicador & Média & DP & Min & Max \\
txurbmun & 0,86 & 0,19 & 0,04 & 1,00 \\
propagricola & 0,10 & 0,13 & 0,00 & 0,80 \\
pop & 1.286 .627 & 2.829 .736 & 805,00 & 11.200 .000 \\
txsuper & 11,18 & 6,97 & 0,28 & 33,68 \\
propformal & 58,34 & 18,03 & 2,97 & 89,11 \\
gini & 0,53 & 0,07 & 0,28 & 0,80 \\
fectot & 1,98 & 0,44 & 1,21 & 4,89 \\
\hline
\end{tabular}

Fonte: elaboração própria a partir de Instituto Brasileiro de Geografia e Estatística (2010). DP significa desvio-padrão; Min significa valor mínimo; Max significa valor máximo.

No que se refere às variáveis de maior interesse neste estudo, observa-se (Figuras 1 e 2) que parcela substancial dos domicílios pobres carecia de acesso a serviços básicos de infraestrutura: 7\% não tinham acesso à energia elétrica; 34\% não possuíam telefone móvel; $32 \%$ não tinham acesso a serviços de telecomunicações (celular ou fixo); $34 \%$ não eram abastecidos com água; 68\% não tinham tratamento de esgoto adequado; e 85\% não possuíam acesso a telefone fixo.

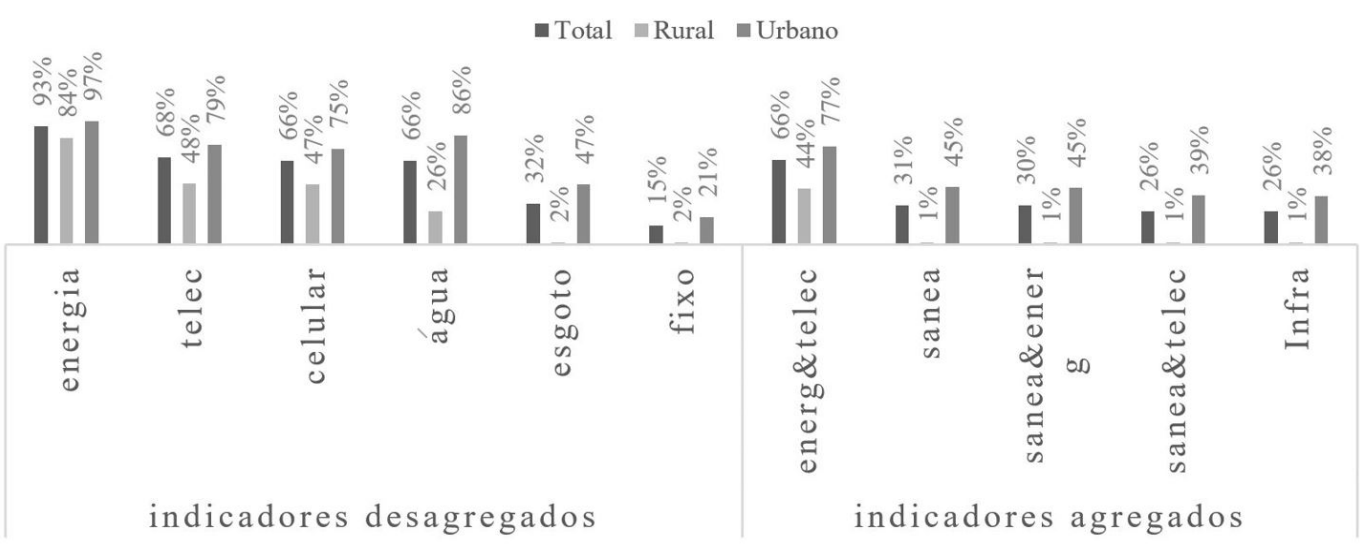

Figura 1 - Acesso à infraestrutura no Brasil: total, rural e urbano (domicílios pobres, 2010). Fonte: elaboração própria a partir de Instituto Brasileiro de Geografia e Estatística (2010).

Ademais, levando-se em consideração o caráter multidimensional da infraestrutura, ou seja, a provisão conjunta de diversos serviços, a situação é ainda mais precária. Apenas $31 \%$ da população era atendida com saneamento básico (água e esgoto); 66\% tinham acesso à 
energia elétrica e telefone fixo e/ou móvel; 30\% tinham acesso a saneamento básico e energia; e $26 \%$ possuíam acesso a serviços de telecomunicações e saneamento ou acesso aos três tipos de serviço conjuntamente.

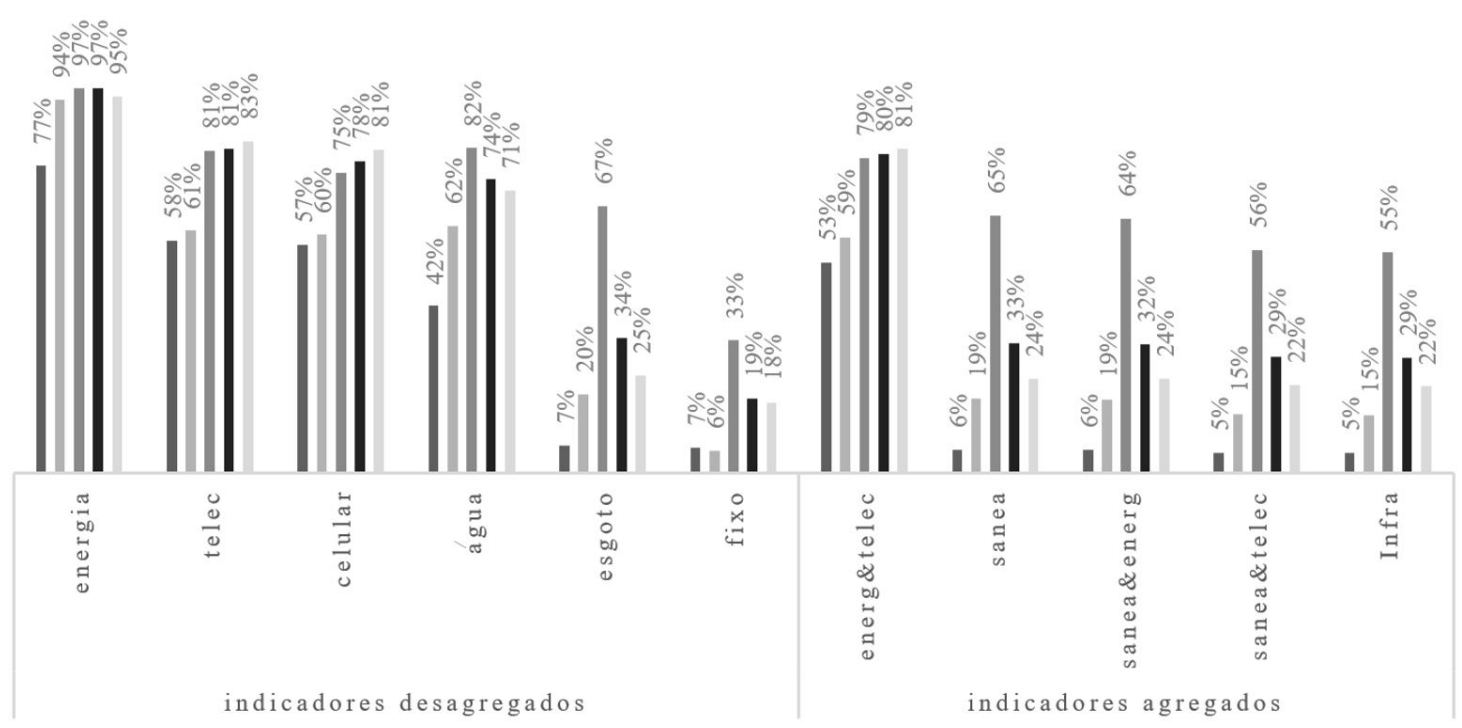

Figura 2 - Acesso à infraestrutura por regiões brasileiras (domicílios pobres, 2010). Fonte: elaboração própria a partir de Instituto Brasileiro de Geografia e Estatística (2010).

As Figuras 1 e 2 ainda exibem as discrepâncias existentes nos contextos rural-urbano e regional. Na primeira comparação, observa-se que domicílios localizados na zona rural possuíam acesso substancialmente menor para todos os tipos serviços analisados em relação àqueles localizados em área urbana. No contexto regional, observa-se que as regiões Norte e Nordeste tinham os piores indicadores para todos os serviços. Esses resultados indicam a importância de se considerar aspectos da localização dos domicílios para explicar as relações entre as variáveis explicativas de infraestrutura e a redução da pobreza.

\subsection{Análise econométrica}

Na Tabela 3, apresenta-se a razão de chances para a pobreza dos domicílios brasileiros. Os modelos, enumerados de 0 (modelo nulo) até 4 (modelo de intercepto e inclinação aleatórios com interações), evoluem de acordo com a inclusão de variáveis explicativas de primeiro e segundo nível. O modelo nulo confirma a existência de efeito aleatório na média da pobreza, dada a significância do intercepto da equação, o qual tem valor alterado com a inclusão das variáveis explicativas.

No modelo 1 (intercepto aleatório), foram incluídas as variáveis representativas das características domiciliares (nível 1), obtendo-se resultado significativo para todas elas. Os resultados indicam que a probabilidade de o domicílio estar em condição de pobreza, em relação a não estar em tal condição, diminui ao passo que o chefe de família: é do sexo masculino; tem idade cada vez mais avançada; é de cor branca; possui nível de escolaridade mais alto; está empregado; e vive com o cônjuge. Ademais, as chances de o domicílio se situar em condição de pobreza aumentam com o maior número de moradores. Tais resultados corroboram aqueles convencionalmente encontrados pela literatura especializada (Schiavon, 2014; Sawada, 2015). Em relação às variáveis explicativas ou variáveis de cunho domiciliar, o sinal e a significância estatística dos seus respectivos parâmetros foram os mesmos nos demais modelos especificados, indicando robustez dos resultados encontrados.

Em relação à variável explicativa de maior interesse neste estudo, infraestrutura, observa-se que o sinal foi esperado e significativo, indicando que o acesso aos serviços de infraestrutura é determinante para diminuir as chances de os domicílios se 
encontrarem em situação de pobreza. Os resultados encontrados nesse sentido corroboram os estudos feitos por Jalan \& Ravallion (2003), Lokshin \& Yemtsov (2004, 2005), Jacoby (2000), Gibson \& Rozelle (2003) e Jacoby \& Minten (2008), entre outros.

Os próximos modelos descritos na Tabela 3, então, têm como objetivo melhor explicar a relação entre redução da pobreza e acesso à infraestrutura, inferindo se existem efeitos heterogêneos dos serviços analisados diante de características socioeconômicas municipais distintas. O modelo 2 apresenta os resultados do modelo de inclinação e intercepto aleatórios, tendo como foco a relação pobreza-acesso à infraestrutura. Os resultados indicam que o coeficiente relacionado à variável infraestrutura diminuiu; em outras palavras, tornou-se mais forte o efeito do acesso aos serviços de infraestrutura sobre a redução da pobreza. Esse resultado aponta a importância de se levar em conta, além de efeitos médios aleatórios (intercepto), efeitos aleatórios referentes ao retorno (inclinação) da variável de infraestrutura sobre a pobreza.

No modelo 3, foram acrescentados indicadores municipais relacionados ao desenvolvimento social do município, à sua condição econômica e a alguns aspectos da realidade do mercado de trabalho. A inclusão dos indicadores municipais alterou a razão de chance da variável de acesso à infraestrutura no nível 1, sendo aceitável a hipótese de que os municípios apresentam valores distintos para a probabilidade da pobreza. Todos os coeficientes foram significativos, exceto aquele referente à variável fecundidade total. Em relação às características locacionais, observa-se que, em municípios com maior percentagem de domicílios localizados na zona rural (menor valor da taxa de urbanização), há aumento na média de domicílios considerados pobres.

Interpretação análoga pode ser feita para as variáveis de proporção de empregados no setor agrícola, proporção de pessoas com ensino superior e proporção de trabalhadores no setor formal. Mesmo que o setor agrícola possa ser considerado de menor produtividade, se comparado ao setor industrial ou o de serviços, os resultados indicam que o fato de o setor prover emprego para as famílias é fator de redução da pobreza. Ainda, municípios com proporção média maior de indivíduos com ensino superior, bem como de maior percentagem média de pessoas trabalhando no setor formal, apresentam diminuição na média de domicílios considerados pobres. Por fim, em municípios com maior população e elevado índice de Gini, há uma ampliação média de domicílios em situação de pobreza. As variáveis municipais tiveram os sinais esperados, com base na literatura especializada, e corroboram as argumentações teóricas gerais feitas por Hulme et al. (2001), Rocha (2006), Haughton \& Khandker (2009), entre outros.

O modelo 4 incluiu, além das características de primeiro e segundo nível, as interações entre a variável de infraestrutura e aquelas de segundo nível, ou seja, busca-se captar efeitos aleatórios de impacto da infraestrutura sobre a pobreza de acordo com as características municipais. Observa-se que houve mudança no coeficiente da variável de infraestrutura e de algumas das variáveis de segundo nível, indicando a importância de se levar em consideração inclinações aleatórias. A variável fecundidade total e as interações da variável infraestrutura com a proporção de pessoas com ensino superior completo e a proporção de trabalhadores empregados no setor formal foram não significativas nessa especificação. Tais resultados reforçam as principais conclusões feitas por Broegaard et al. (2011) e Rauniyar et al. (2011), as quais indicam que os efeitos do acesso à infraestrutura sobre a redução da pobreza, de fato, variam de acordo com o contexto municipal em que os pobres estão inseridos. 
Tabela 3 - Estimativas dos modelos logísticos hierárquicos para a pobreza no Brasil, 2010.

\begin{tabular}{|c|c|c|c|c|c|c|c|c|c|c|}
\hline \multirow[b]{2}{*}{$\begin{array}{c}\text { Variáveis } \\
\text { explicativas }\end{array}$} & \multicolumn{2}{|c|}{ Modelo 0 (Nulo) } & \multicolumn{2}{|c|}{ Modelo 1} & \multicolumn{2}{|c|}{ Modelo 2} & \multicolumn{2}{|c|}{ Modelo 3} & \multicolumn{2}{|c|}{ Modelo 4} \\
\hline & $\begin{array}{l}\text { Odds } \\
\text { ratio }\end{array}$ & $\begin{array}{l}\text { Desvio- } \\
\text { padrão }\end{array}$ & $\begin{array}{l}\text { Odds } \\
\text { ratio }\end{array}$ & $\begin{array}{l}\text { Desvio- } \\
\text { padrão }\end{array}$ & $\begin{array}{l}\text { Odds } \\
\text { ratio }\end{array}$ & $\begin{array}{l}\text { Desvio- } \\
\text { padrão }\end{array}$ & $\begin{array}{l}\text { Odds } \\
\text { ratio }\end{array}$ & $\begin{array}{l}\text { Desvio- } \\
\text { padrão }\end{array}$ & $\begin{array}{l}\text { Odds } \\
\text { ratio }\end{array}$ & $\begin{array}{l}\text { Desvio- } \\
\text { padrão }\end{array}$ \\
\hline Intercepto & 0,195 & 0,003 & 2,893 & 0,052 & 2,914 & 0,052 & 6,254 & 0,783 & 6,109 & 0,766 \\
\hline $\begin{array}{l}\text { Características do } \\
\text { sexochefam } \\
\text { idadechefea }\end{array}$ & miciliares & & 0,843 & 0,004 & 0,845 & 0,004 & 0,844 & 0,004 & 0,844 & 0,004 \\
\hline 1 & & & 0,860 & 0,004 & 0,860 & 0,004 & 0,861 & 0,004 & 0,861 & 0,004 \\
\hline 2 & & & 0,577 & 0,003 & 0,577 & 0,003 & 0,578 & 0,003 & 0,578 & 0,003 \\
\hline 3 & & & 0,406 & 0,002 & 0,405 & 0,002 & 0,406 & 0,002 & 0,406 & 0,002 \\
\hline 4 & & & 0,101 & 0,001 & 0,100 & 0,001 & 0,100 & 0,001 & 0,100 & 0,001 \\
\hline corchefa & & & 0,848 & 0,003 & 0,848 & 0,003 & 0,851 & 0,003 & 0,851 & 0,003 \\
\hline $\begin{array}{l}\text { companheiro } \\
\text { escchefea }\end{array}$ & & & 0,633 & 0,003 & 0,632 & 0,003 & 0,632 & 0,003 & 0,632 & 0,003 \\
\hline 2 & & & 0,477 & 0,003 & 0,478 & 0,003 & 0,478 & 0,003 & 0,478 & 0,003 \\
\hline 3 & & & 0,217 & 0,001 & 0,217 & 0,001 & 0,217 & 0,001 & 0,217 & 0,001 \\
\hline 4 & & & 0,059 & 0,001 & 0,059 & 0,001 & 0,059 & 0,001 & 0,059 & 0,001 \\
\hline empchefea & & & 0,060 & 0,000 & 0,060 & 0,000 & 0,060 & 0,000 & 0,060 & 0,000 \\
\hline moradores & & & 1,419 & 0,002 & 1,420 & 0,002 & 1,419 & 0,002 & 1,419 & 0,002 \\
\hline Infraestrutura & & & 0,417 & 0,002 & 0,395 & 0,004 & 0,412 & 0,004 & 0,453 & 0,068 \\
\hline Características m & unicipais & & & & & & & & & \\
\hline txurbmun & & & & & & & 0,672 & 0,041 & 0,643 & 0,039 \\
\hline propagricola & & & & & & & 0,281 & 0,027 & 0,286 & 0,027 \\
\hline Inpop & & & & & & & 1,043 & 0,009 & 1,047 & 0,009 \\
\hline fectot & & & & & & & $0,998^{\text {ns }}$ & 0,019 & $0,987^{\text {ns }}$ & 0,018 \\
\hline txsuper & & & & & & & 0,938 & 0,003 & 0,938 & 0,003 \\
\hline propformal & & & & & & & 0,960 & 0,001 & 0,960 & 0,001 \\
\hline gini & & & & & & & 22,520 & 3,632 & 25,150 & 4,064 \\
\hline Interações & & & & & & & & & & \\
\hline txurbmuninfra & & & & & & & & & 1,919 & 0,152 \\
\hline propagricolainfra & & & & & & & & & 0,756 & 0,091 \\
\hline Inpopinfra & & & & & & & & & 0,963 & 0,009 \\
\hline fectotinfra & & & & & & & & & 1,099 & 0,028 \\
\hline txsuperinfra & & & & & & & & & $1,005^{\text {ns }}$ & 0,003 \\
\hline propformalinfra & & & & & & & & & $1,001^{\text {ns }}$ & 0,001 \\
\hline giniinfra & & & & & & & & & 0,437 & 0,087 \\
\hline $\begin{array}{l}\text { Observações: } \\
4120620 ;\end{array}$ & $\begin{array}{c}\text { Grupos: } \\
5565\end{array}$ & & & & & & & & & \\
\hline
\end{tabular}

Fonte: resultados da pesquisa. Nota: ${ }^{\text {ns }}$ não significativo estatisticamente.

A interação entre as variáveis taxa de urbanização e infraestrutura indica que, quanto menor a taxa de urbanização do município, maior o impacto positivo do acesso à infraestrutura sobre a pobreza. Esse resultado era esperado, dada a discrepância no contexto rural-urbano observada na análise descritiva aqui discutida. O transbordamento da infraestrutura para áreas rurais poderia ter papel ainda mais efetivo em reduzir a pobreza por causa do grande número de pessoas sem acesso e também do maior nível de pobreza nessas localidades. Relação similar é encontrada na interação entre a variável proporção de empregados no setor agrícola e infraestrutura, o que indica que, quanto maior a proporção da população ocupada no setor agrícola, maior o impacto positivo do acesso aos serviços básicos de infraestrutura sobre a redução da pobreza. Como argumentam Ali \& Pernia (2003), o crescimento da produtividade agrícola, proporcionado por expansão da infraestrutura, é um dos motores de redução da pobreza, via propagações diretas sobre o salário e criação de empregos, além de influências indiretas sobre a ampliação da atividade econômica. Além disso, ao passo que mais indivíduos vivem e/ou trabalham em áreas rurais, os efeitos positivos do acesso à infraestrutura sobre a redução da pobreza são reforçados. 
O efeito da interação entre o logaritmo natural da população e a variável infraestrutura, por sua vez, é o de potencializar o efeito positivo do acesso à infraestrutura sobre a redução da pobreza. De outra forma, quanto maior a população do município, maiores tendem a ser os retornos da infraestrutura sobre as chances de os domicílios estarem fora da situação de pobreza. Esse resultado é coerente com as características físicas e econômicas dos setores de infraestrutura analisados neste estudo. Setores como os de saneamento básico, energia e telecomunicações são caracterizados por altos investimentos necessários para iniciar a operação e por tempo elevado para que o investimento gere retornos financeiros. Tais setores configuram um monopólio natural, no qual a firma responsável pela prestação dos serviços será sustentável e eficiente economicamente apenas quando usufruir de grandes economias de escala, o que pode ser obtido quando a população do município é elevada. Desta forma, o fato de o município possuir grande população pode facilitar a instalação dos serviços, potencializando o efeito positivo deles sobre a redução da pobreza. Argumentação mais detalhada neste sentido pode ser encontrada em Galvão Junior \& Paganini (2009), por exemplo.

Em relação à interação entre o índice de Gini e a infraestrutura, observa-se que o fato de o município ser mais desigual potencializa a relação positiva entre o acesso à infraestrutura e a redução da pobreza. Com base na análise descritiva feita anteriormente, argumenta-se que os domicílios pobres se situam em municípios com mais alta desigualdade de renda e possuem menor acesso a todos os serviços de infraestrutura. Desta forma, a transmissão desses serviços em cidades mais desiguais poderia estar fortemente ligada ao transbordamento deles para as classes de renda mais baixa, o que aumentaria o benefício do acesso à infraestrutura sobre a redução da pobreza. Uma questão natural a ser colocada e estudada em trabalhos posteriores está relacionada à possibilidade de municípios mais desiguais serem mais seletivos nos projetos de infraestrutura, ou seja, há a tendência de os investimentos nos setores envolvidos se concentrarem em localidades com população mais rica e maior poder de pressionar as autoridades públicas responsáveis dentro dos próprios municípios.

Por fim, enquanto a variável fecundidade total não foi significativa em todas as especificações, a interação dela com a variável infraestrutura se mostrou significativa. Municípios com taxa de fecundidade maior enfraquecem o impacto positivo do acesso à infraestrutura sobre a pobreza. Como esperado, em municípios de crescimento populacional mais elevado, podem ocorrer problemas de congestão de infraestrutura, ou seja, ainda que existam investimentos em expansão e manutenção dos serviços, à medida que se aumenta o número de usuários dos equipamentos de infraestrutura, reduz-se a capacidade destes de prover os serviços para os quais foram destinados. Uma outra pergunta a ser inserida e que também pode receber destaque em trabalhos posteriores é se esse fenômeno estaria associado ao fato de municípios com maior fecundidade necessitarem de maior oferta e qualidade dos serviços de infraestrutura, principalmente aqueles relacionados à saúde das crianças e mães em estado de gestação, notadamente os serviços de água e esgoto.

Em termos de políticas públicas, percebe-se que a busca pela universalização da oferta de serviços básicos de infraestrutura pode trazer benefícios em termos de redução da pobreza no Brasil. Os impactos positivos, neste sentido, podem ser reforçados de acordo com as características municipais referentes ao tamanho da população, desigualdade de renda, proporção de indivíduos trabalhando e vivendo na zona rural, e nível de fecundidade total, as quais devem ser levadas em consideração pelas autoridades políticas responsáveis pela articulação e disposição dos setores envolvidos.

\section{Conclusões}

O presente trabalho teve como objetivo verificar se há relação entre o acesso à infraestrutura e a redução da pobreza nos domicílios brasileiros, em uma abordagem que analisa a pobreza em perspectiva contextual, ou seja, considera-se, além de questões de renda e desigualdade dela, características socioeconômicas do local em que o domicílio está inserido. Este trabalho avança na literatura sobre infraestrutura e pobreza ao captar, além dos efeitos das covariadas domiciliares acerca da pobreza, as interações entre as variáveis 
independentes contextuais ou municipais com o acesso à infraestrutura. Neste sentido, o estudo demonstra se os efeitos do acesso dos domicílios às infraestruturas básicas se dão de forma heterogênea, ou seja, se variam de acordo com o nível de desigualdade de renda, a estrutura do mercado de trabalho, as condições de educação e saúde do município etc.

Com base em modelos logísticos hierárquicos, estimaram-se os determinantes da pobreza em âmbito municipal e domiciliar, corrigindo para problemas de agrupamento dos dados em diferentes níveis. Os principais resultados demonstram que a probabilidade de o domicílio estar em condição de pobreza, em relação a não estar em tal condição, diminui ao passo que o chefe de família: é do sexo masculino; tem idade cada vez mais avançada; é de cor branca; possui nível de escolaridade mais alto; está empregado; e vive com o cônjuge. Ademais, as chances de o domicílio se situar em condição de pobreza aumentam com o maior número de moradores. Em relação à variável explicativa de maior interesse neste estudo, acesso à infraestrutura, observa-se que o sinal foi esperado e significativo, indicando que o acesso aos serviços básicos analisados é determinante para diminuir as chances de os domicílios se encontrarem em situação de pobreza.

A inclusão dos indicadores municipais alterou a razão de chance da variável de acesso à infraestrutura no nível 1, sendo aceitável a hipótese de que os municípios apresentam valores distintos para a probabilidade da pobreza. Todos os coeficientes foram significativos, exceto aquele referente à variável fecundidade total. Desta forma, argumenta-se que, em municípios com maior proporção de domicílios em áreas urbanas, de empregados no setor agrícola, da população com ensino superior e de pessoas trabalhando no setor formal, há diminuição na média de domicílios considerados pobres. O mesmo ocorre para municípios com menor desigualdade de renda e maior população.

Ademais, testou-se a existência de efeitos heterogêneos do acesso à infraestrutura sobre a redução da pobreza, de acordo com as características socioeconômicas municipais, sendo geradas interações entre as variáveis de segundo nível e a variável proxy para infraestrutura. Os resultados mais importantes neste sentido indicam que o efeito positivo do acesso à infraestrutura sobre a redução da pobreza é potencializado em municípios com maior proporção de indivíduos residentes em zona rural e trabalhando no setor agrícola, maior Índice de Gini, maior população e menor taxa de fecundidade.

Conclui-se que a expansão dos investimentos e, consequentemente, do acesso dos domicílios à infraestrutura é essencial para a redução da pobreza no Brasil. Os responsáveis pelas políticas públicas de infraestrutura devem levar em consideração, além dos efeitos diretos da infraestrutura sobre a pobreza, o fato de que tais efeitos são reforçados ou limitados de acordo com as características socioeconômicas do município onde os domicílios estão inseridos.

Cabe mencionar que algumas questões consideradas importantes para a investigação sobre infraestrutura e pobreza não foram levadas em consideração neste trabalho. Como proposta para pesquisas futuras, indica-se a inclusão de outras características da infraestrutura além do acesso, tais como a oferta e a qualidade dos setores de transportes, energia, telecomunicações e saneamento, atributos que podem ser importantes para explicar a pobreza domiciliar. Ademais, uma análise temporal seria relevante para analisar os efeitos da infraestrutura sobre a dinâmica da pobreza brasileira, mais do que sobre o nível de pessoas consideradas pobres em determinado período de tempo.

\section{Referências Bibliográficas}

Aldrich, J. H., \& Nelson, F. D. (1984). Linear probability, logit, and probit models (94 p.). London: Sage.

Ali, I., \& Pernia, E. M. (2003). Infrastructure and poverty reduction: what is the connection? (ERD Policy Brief, No. 13). Manila: Economics and Research Department, Asian Development Bank.

Aschauer, D. (1989). Is public expenditure productive? Journal of Monetary Economics, 23(2), 177-200. http://dx.doi.org/10.1016/0304-3932(89)90047-0

Banerjee, A. (2004). Who is getting the public goods in India? Some evidence and some speculation. In K. Basu (Ed.), India's emerging economy: performance and prospects in the 1990's and beyond. Cambridge: MIT Press. 
Brasil. Ministério do Desenvolvimento Social e Combate à Fome. (2011). Plano Brasil Sem Miséria. Brasília: MDS. Recuperado em 22 de outubro de 2018, de http://www.mds.gov.br/webarquivos/publicacao/brasil_sem_miseria/livro_o_brasil_sem_miseria/liv ro_obrasilsemmiseria.pdf

Broegaard, E., Freeman, T., \& Schwensen, C. (2011). Experience from a phased mixed-methods approach to impact evaluation of Danida support to rural transport infrastructure in Nicaragua. Journal of Development Effectiveness, 3(1), 9-27. http://dx.doi.org/10.1080/19439342.2010.545893

Calderón, C., \& Servén, L. (2014). Infrastructure, growth, and inequality: an overview (World Bank Policy Research Working Paper, No. 7034). Washington: The World Bank.

Cruz, A. C., Torres, D. A. R., \& Teixeira, E. C. (2017). Public Expenditure on infrastructure and human capital as a form of promotion of pro-poor growth in the Brazilian states. Análise Econômica, 35(67), 237-267.

Dinkelman, T. (2011). The effects of rural electrification on employment: new evidence from South Africa. The American Economic Review, 101(7), 3078-3108.

Estache, A. (2010). A survey of impact evaluation of infrastructure projects, programs and policies (ECARES Working Paper, No. 2010-005). Brussels: European Center for Advanced Research in Economics and Statistics.

Estache, A., \& Fay, M. (2007). Current debates on infrastructure policy (World Bank Policy Research Working Paper, No. 4410). Washington: The World Bank.

Expert Group on Poverty Statistics. (2006). Compendium of best practices in poverty measurement. Rio de Janeiro: Rio Group.

Galvão Junior, A., \& Paganini, W. D. S. (2009). Conceptual aspects of the regulation of water and sewage services in Brazil. Engenharia Sanitaria e Ambiental, 14(1), 79-88.

Gibson, J., \& Rozelle, S. (2003). Poverty and access to roads in Papua New Guinea. Economic Development and Cultural Change, 52(1), 159-185.

Gonzalez-Navarro, M., \& Quintana-Domeque, C. (2015). Paving streets for the poor: experimental analysis of infrastructure effects (Discussion Paper Series, No. 757). Oxford: Department of Economics, University of Oxford.

Guo, G., \& Zhao, H. (2000). Multilevel modeling for binary data. Annual Review of Sociology, 26(1), 441 462.

Hansen, H., Andersen, O. W., \& White, H. (2011). Impact evaluation of infrastructure interventions. Journal of Development Effectiveness, 3(1), 1-8.

Haughton, J., \& Khandker, S. (2009). Handbook on poverty and inequality. Washington: The World Bank.

Hox, J. (1998). Multilevel modeling: when and why. In I. Balderjahn \& R. Mathar (Eds.), Classification, data analysis, and data highways (1st ed., Chap. 17, pp. 147-154). Berlin: Springer.

Hox, J. (2017). Multilevel analysis: techniques and applications (3rd ed.). New York: Routledge.

Hulme, D., Moore, K., \& Shepherd, A. (2001). Chronic poverty: meanings and analytical frameworks (CPRC Working Paper, No. 2). Manchester: IDPM, University of Manchester.

Instituto Brasileiro de Geografia e Estatística - IBGE. (2010). Censo demográfico 2010. Rio de Janeiro.

Jacoby, H. (2000). Access to markets and the benefits of rural roads. Economic Journal, 110(465), 713737.

Jacoby, H., \& Minten, B. (2008). On measuring the benefits of lower transport costs (Policy Research Working Paper, No. WPS 4484). Washington: The World Bank.

Jalan, J., \& Ravallion, M. (2002). Geographic poverty traps? A micro model of consumption growth in rural china. Journal of Applied Econometrics, 17(4), 329-346.

Jalan, J., \& Ravallion, M. (2003). Does piped water reduce diarrhea for children in rural India? Journal of Econometrics, 112(1), 153-173.

Jerome, A. (2011). Infrastructure, economic growth and poverty reduction in Africa. Journal of Infrastructure Development, 3(2), 127-151.

Jones, S. (2011). Infrastructure to support inclusive growth and poverty reduction, infrastructure for supporting inclusive growth and poverty reduction in Asia. In Asian Development Bank (Ed.), Infrastructure for supporting inclusive growth and poverty reduction in Asia (pp. 9-13). Philippines: ADB. 
Khandker, S., \& Koolwal, G. (2007). Are pro-growth policies pro-poor? Evidence from Bangladesh. Washington: The World Bank.

Lima, A. C. C., \& Simões, R. F. (2010). Teorias clássicas do desenvolvimento regional e suas implicações de política econômica: o caso do Brasil. Revista de Desenvolvimento Econômico, 12(21), 5-19.

Lokshin, M., \& Yemtsov, R. (2004). Combining longitudinal household and community surveys for evaluation of social transfers: Infrastructure rehabilitation projects in rural Georgia. Journal of Human Development, 5(2), 265-277. http://dx.doi.org/10.1080/1464988042000225168

Lokshin, M., \& Yemtsov, R. (2005). Has rural infrastructure rehabilitation in georgia helped the poor? The World Bank Economic Review, 19(2), 311-333. http://dx.doi.org/10.1093/wber/lhi007

López, H. (2004). Pro-poor-pro-growth: is there a trade-off? (World Bank Policy Research Working Paper, No. 3378). Washington: The World Bank. http://dx.doi.org/10.1596/1813-9450-3378.

Marinho, E., Campelo, G., França, J., \& Araujo, J. (2017). Impact of infrastructure expenses in strategic sectors for Brazilian poverty. Revista Economia da ANPEC, 18, 244-259.

Myrdal, G. (1957). Economic theory and underdeveloped regions. London: Gerald Duckworth \& CO.

North, D. C. (1977). Teoria da localização e crescimento econômico regional. In J. Schwartzman (Ed.), Economia regional: textos escolhidos. Belo Horizonte: Cedeplar.

Raiser, M., Clarke, R., Procee, P., Briceno-Garmendia, C., Kikoni, E., Kizito, J., \& Vinuela, L. (2017). Back to planning: how to close Brazil's infrastructure gap in times of austerity. Washington: World Bank Group.

Rauniyar, G., Orbeta Junior, A., \& Sugiyarto, G. (2011). Impact of water supply and sanitation assistance on human welfare in rural Pakistan. Journal of Development Effectiveness, 3(1), 62-102.

Ravallion, M. (2004). Pro-poor growth: a primer (World Bank Policy Research Working Paper, No. 3242). Washington: World Bank Group.

Rocha, S. (2006). Pobreza no Brasil: afinal de que se trata? Rio de Janeiro: FGV.

Saiani, C. C. S., Toneto Júnior, R., \& Dourado, J. (2013). Desigualdade de acesso a serviços de saneamento ambiental nos municípios brasileiros: evidências de uma Curva de Kuznets e de uma Seletividade Hierárquica das Políticas. Nova Economia, 23(3), 657-692. http://dx.doi.org/10.1590/S0103-63512013000300006

Sawada, Y. (2015). The impacts of infrastructure in development: a selective survey (ADBI Working Paper, No. 511). Tokyo: Asian Development Bank Institute. Recuperado em 22 de outubro de 2018, de http://www.adbi.org/working-paper/2015/01/20/6526.impacts.infrastructure.in.dev/

Schiavon, L. C. (2014). Pobreza e diversidades regionais: uma investigação empírica. Novas Edições Acadêmicas.

Sen, A. (2000). Desenvolvimento como liberdade. São Paulo: Companhia das Letras.

Seneviratne, D., \& Sun, Y. (2013). Infrastructure and income distribution in ASEAN-5: what are the links? (IMF Working Paper, No. 13/41). International Monetary Fund.

United Nations. (2000). United Nations Millennium Declaration Resolution adopted by the General Assembly. Recuperado em 22 de outubro de 2018, de http://www.un.org/millennium/declaration/ares552e.pdf

Willoughby, C. (2004). Infrastructure and the millennium development goals: background paper for the october 2004 Berlin meeting of the POVNET infrastructure working group. Washington: World Bank Group.

Submetido 23/Maio/2018

Aceito 21/Abr./2019

Classificação JEL: H54; 138; 018 


\section{APÊNDICE}

Quadro 1A - Variáveis utilizadas na análise descritiva e/ou modelos hierárquicos.

\begin{tabular}{|c|c|c|}
\hline Tipo & Variável & Definição \\
\hline \multirow[t]{4}{*}{ Dependente } & rendfampc & Rendimento domiciliar mensal per capita. \\
\hline & & 1, se rendfampc inferior a 140; 0, se for o contrário. \\
\hline & sexochefam & 1, se o chefe da família for do \\
\hline & & 0 (grupo de referência), chefes cc \\
\hline \multirow{6}{*}{ 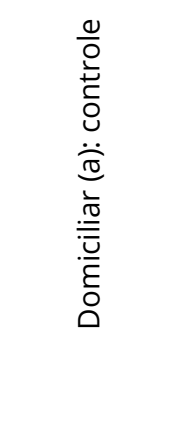 } & idadechefea & $\begin{array}{c}40 \text { anos; } 2 \text {, chefes entre } 41 \text { e } 50 \text { anos; } 3 \text {, chefes entre } 51 \text { e } 60 \text { anos; } 4 \text {, } \\
\text { chefes com mais de } 60 \text { anos. }\end{array}$ \\
\hline & companheiro & $\begin{array}{l}\text { 1, caso o chefe do domicílio viva em companhia de um cônjuge ou } \\
\text { companheiro. }\end{array}$ \\
\hline & escchefea & $\begin{array}{l}1 \text { (grupo de referência), sem instrução e fundamental incompleto; } 2 \text {, } \\
\text { fundamental completo e médio incompleto; 3, médio completo e superior } \\
\text { incompleto; } 4 \text {, superior completo. }\end{array}$ \\
\hline & empchefea & 1 , se chefe estiver empregado; 0 , se for o contrário. \\
\hline & corchefea & 1, se chefe for branco; 0 , se for o contrário. \\
\hline & moradores & Núme \\
\hline \multirow{11}{*}{ 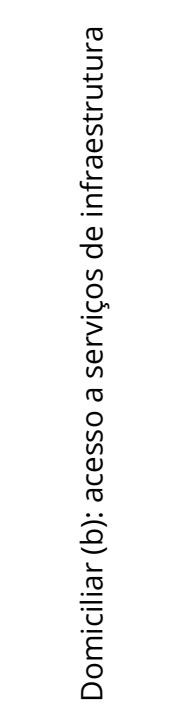 } & água & $\begin{array}{l}\text { 1, se o domicílio for atendido pela rede geral de abastecimento de água; } \\
\text { 0, se for o contrário. }\end{array}$ \\
\hline & esgoto & 1, se o domicílio for atendido pelo sistema de coleta; 0 , se for o contrário. \\
\hline & sanea & 1, se o domicílio possuir acesso à água e esgoto; 0, se for o contrário. \\
\hline & energia & $\begin{array}{c}1 \text { se o domicílio possuir acesso à energia elétrica por companhia } \\
\text { distribuidora; } 0 \text {, se for o contrário. }\end{array}$ \\
\hline & fixo & 1, se o domicílio possuir telefone fixo \\
\hline & celular & 1, se o domicílio possuir telefone móvel; 0 , se for o contrário. \\
\hline & telec & 1, se o domicílio possuir telefone fixo ou móvel; 0 , se for o contrário. \\
\hline & sanea\&energ & $\begin{array}{l}\text { 1, se o domicílio possuir acesso aos serviços de saneamento e energia; } \\
\qquad \text {, se for o contrário. }\end{array}$ \\
\hline & sanea\&telec & $\begin{array}{r}\text { 1, se o domicílio possuir acess } \\
\text { telecomunicações; }\end{array}$ \\
\hline & energ\&telec & $\begin{array}{l}\text { 1, se o domicílio possuir acesso aos serviços de energia e } \\
\text { telecomunicações; } 0 \text {, se for o contrário. }\end{array}$ \\
\hline & infraestrutura & $\begin{array}{c}\text { 1, se o domicílio possuir acesso aos serviços de energia, telecomunicações } \\
\text { e saneamento; } 0 \text {, se for o contrário. }\end{array}$ \\
\hline \multirow{6}{*}{ 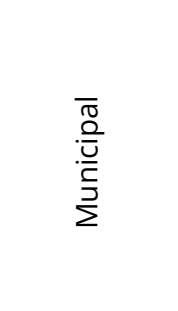 } & txurbmun & Percentual de indivíduos residentes em zona urbana. \\
\hline & propagricola & Percentual de indivíduos trabalhando no setor agrícola. \\
\hline & Inpop & Logaritmo natural da população. \\
\hline & fectot & Taxa de fecundidade total. \\
\hline & txsuper & Percentual da população com ensino superior completo. \\
\hline & $\begin{array}{l}\text { propformal } \\
\text { gini }\end{array}$ & $\begin{array}{l}\text { Grau de formalização dos ocupados - } 18 \text { anos ou mais. } \\
\text { Índice de Gini segundo renda domiciliar per capita. }\end{array}$ \\
\hline
\end{tabular}

Fonte: Instituto Brasileiro de Geografia e Estatística (2010). 
Tabela 2A - População atendida com serviços de infraestrutura (\%), domicílios não pobres e amostra completa, 2010.

\begin{tabular}{|c|c|c|c|c|c|c|c|c|c|c|c|c|}
\hline Variável & Amostra & $\frac{\text { 悉 }}{\stackrel{8}{8}}$ & 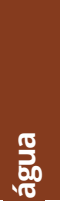 & $\begin{array}{l}\text { 영 } \\
\text { 뭉 }\end{array}$ & $\frac{000}{\frac{0}{0}}$ & $\frac{\mathrm{d}}{\mathrm{d}}$ & $\stackrel{8}{x}$ & $\frac{\frac{1}{5}}{\frac{2}{2}}$ & 异 & 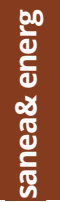 & 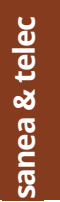 & 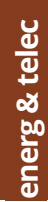 \\
\hline \multirow{2}{*}{ Total } & Completa & 54 & 83 & 55 & 98 & 88 & 41 & 83 & 51 & 54 & 51 & 87 \\
\hline & Não pobres & 58 & 86 & 60 & 99 & 91 & 45 & 86 & 55 & 58 & 55 & 91 \\
\hline \multirow{2}{*}{ Rural } & Completa & 2 & 27 & 3 & 90 & 63 & 7 & 61 & 2 & 2 & 2 & 60 \\
\hline & Não pobres & 3 & 28 & 4 & 93 & 71 & 9 & 68 & 2 & 3 & 3 & 68 \\
\hline \multirow{2}{*}{ Urbano } & Completa & 62 & 92 & 64 & 99 & 92 & 46 & 87 & 59 & 62 & 59 & 91 \\
\hline & Não pobres & 64 & 92 & 66 & 99 & 94 & 50 & 88 & 61 & 64 & 62 & 93 \\
\hline \multirow{2}{*}{ Norte } & Completa & 12 & 54 & 14 & 90 & 78 & 20 & 77 & 11 & 12 & 11 & 75 \\
\hline & Não pobres & 14 & 58 & 17 & 94 & 86 & 25 & 83 & 13 & 14 & 13 & 83 \\
\hline \multirow{2}{*}{ Nordeste } & Completa & 32 & 76 & 34 & 97 & 77 & 21 & 75 & 29 & 32 & 29 & 76 \\
\hline & Não pobres & 38 & 81 & 40 & 98 & 84 & 27 & 81 & 35 & 38 & 35 & 83 \\
\hline \multirow{2}{*}{ Sudeste } & Completa & 79 & 90 & 81 & 99 & 93 & 56 & 86 & 75 & 79 & 75 & 92 \\
\hline & Não pobres & 81 & 91 & 82 & 99 & 94 & 58 & 87 & 77 & 80 & 77 & 94 \\
\hline \multirow{2}{*}{ Sul } & Completa & 44 & 85 & 46 & 99 & 94 & 43 & 88 & 43 & 44 & 43 & 93 \\
\hline & Não pobres & 45 & 86 & 47 & 99 & 94 & 45 & 89 & 44 & 45 & 44 & 94 \\
\hline \multirow{2}{*}{ Centro-Oeste } & Completa & 37 & 82 & 38 & 98 & 93 & 36 & 91 & 36 & 37 & 36 & 92 \\
\hline & Não pobres & 39 & 83 & 40 & 99 & 94 & 38 & 92 & 38 & 38 & 38 & 94 \\
\hline
\end{tabular}

Fonte: elaboração própria a partir de Instituto Brasileiro de Geografia e Estatística (2010). 